\title{
Anti-Obesity Medications: An Update for Canadian Physicians
}

Renuca Modi, MD, CCFP'1,2,3, Rameez Kabani, MD, Jerry T. Dang, MD ${ }^{5}$, Sarah Chapelsky, MSc, MD ${ }^{1,6}$, Arya M. Sharma, MD, FRCPC ${ }^{6,7}$

${ }^{1}$ Diplomate of the American Board of Obesity Medicine; ${ }^{2}$ Department of Family Medicine, University of Alberta, Edmonton, AB, Canada; ${ }^{3}$ Edmonton Adult Bariatric Specialty Clinic, Royal Alexandra Hospital, Edmonton, AB, Canada; ${ }^{4}$ Division of General Internal Medicine, Department of Medicine, University of Calgary, Calgary, AB, Canada; ${ }^{5}$ Division of General Surgery, Department of Surgery, University of Alberta, Edmonton, AB, Canada; ${ }^{6}$ EABSC, Royal Alexandra Hospital, Edmonton, AB, Canada; ${ }^{7}$ Division of Endocrinology and Metabolism, Department of Medicine, University of Alberta, Edmonton, AB, Canada

Corresponding Author: Renuca Modi: renuca@ualberta.ca

Submitted: 22 September 2019; Accepted: 17 December 2019; Published: 18 November 2020.

DOI: http://dx.doi.org/10.22374/cjgim.v15i4.394

\section{ABSTRACT Objective}

To review for Canadian physicians the latest pharmacological options for obesity management.

\section{Quality of Evidence}

A literature search was conducted in PubMed with no time restriction. Canadian and international guidelines referenced. National and international statistics databases quoted for epidemiological data. Levels of evidence range from I to III.

\section{Main Message}

As a chronic progressive disease affecting over 7.2 million Canadians, obesity requires early identification and treatment by primary care practitioners. Three anti-obesity medications are approved for use in Canada under the tradenames Xenical ${ }^{\oplus}$, Saxenda ${ }^{\circledR}$, and Contrave ${ }^{\varpi}$ which help bridge the gap between non-pharmacological and surgical options for the treatment of obesity. Family physicians are front-line members of the obesity management team and should remain updated on the pharmacological options for weight management.

\section{Conclusion}

Anti-obesity medications lead to greater average weight loss when combined with behavior modifications and provide individuals with excess weight a sustainable option for obesity management.

\section{RESUME \\ Objectif}

Examiner, à l'intention des médecins canadiens, les dernières options pharmacologiques pour la gestion de l'obésité. 


\section{Qualité des preuves}

Une recherche documentaire a été effectuée dans PubMed sans restriction de temps. Les lignes directrices canadiennes et internationales sont référencées. Bases de données statistiques nationales et internationales citées pour les données épidémiologiques. Les niveaux de preuve vont de I à III.

\section{Message principal}

En tant que maladie chronique progressive touchant plus de 7,2 millions de Canadiens, lobésité nécessite un dépistage et un traitement précoces par les praticiens de soins primaires. Trois médicaments contre lobésité sont approuvés au Canada sous les noms commerciaux Xenical ${ }^{\oplus}$, Saxenda ${ }^{\circledast}$ et Contrave ${ }^{\oplus}$, qui aident à combler le fossé entre les options non pharmacologiques et chirurgicales pour le traitement de l'obésité. Les médecins de famille sont des membres de première ligne de l'équipe de gestion de l'obésité et doivent se tenir au courant des options pharmacologiques pour la gestion du poids.

\section{Conclusion}

Les médicaments contre l'obésité entraînent une perte de poids moyenne plus importante lorsqu'ils sont associés à des modifications du comportement et offrent aux personnes en surpoids une option durable pour la gestion de l’obésité.

\section{Introduction}

Obesity is a complex, progressive chronic disease with serious health consequences. In Canada, obesity rates in adults have increased by $18 \%$ since 2009; more than 7.2 million Canadian adults have obesity. ${ }^{1}$ This growing epidemic has led multiple health organizations, including the Canadian Medical Association and Obesity Canada, to recognize obesity as a chronic disease requiring enhanced research, treatment, and prevention efforts. ${ }^{2}$

As a leading cause of type 2 diabetes, hypertension, cardiovascular disease, stroke, osteoarthritis, sleep apnea, and a wide range of cancers, the early identification and treatment of obesity should be a top priority among healthcare professionals. ${ }^{3}$ Beyond its effects on physical health, obesity also has a significant impact on mental health, social well-being, and economic success due to the widespread weight bias and the negative stigma associated with this chronic illness. ${ }^{4,5}$ Behavioral modification alone has proven inadequate in addressing the obesity epidemic, generally resulting in little more than $3-5 \%$ sustainable weight loss (in spite of greater weight loss in the short term). ${ }^{6}$ Although bariatric surgery is the most effective treatment for long-term weight management, only 1 of 183 eligible Canadians can access this treatment annually (with wide disparities between provinces). ${ }^{7}$ Thus, there remains a significant gap between nonpharmacological and surgical obesity management.

The aim of this review was to inform physicians of the recently approved pharmacological options for weight management including their mode of action, efficacy, and safety profiles.

\section{Quality of Evidence}

A PubMed literature search was conducted with no time restriction using search terms such as obesity, weight loss, treatment, medication, clinical trial, and review. This yielded over 100 relevant articles, of which 20 were reviewed in detail. Canadian and international guidelines on the treatment of obesity were also reviewed. In addition, a supplemental search of references from selected articles and associated reference lists was performed. National and international statistics databases were reviewed for relevant epidemiological data. Finally, expert opinions of Canadian obesity medicine physicians shared at the 6th Canadian Obesity Summit (Ottawa, Ontario, 2019) were included to provide a current and relevant overview of obesity treatment in Canada.

\section{Main Message \\ Recent history of obesity medications in Canada}

In 2010, the serotonin-norepinephrine reuptake inhibitor, sibutramine (Meridia), was voluntarily withdrawn from the Canadian market after a randomized controlled trial (RCT) showed that excess nonfatal cardiovascular events were associated with this medication in individuals at a high risk for cardiovascular disease. ${ }^{8}$ This left the gastric and pancreatic lipase inhibitor, orlistat $\left(\mathrm{Xenical}^{\circledR}\right)$, as the only obesity medication available in Canada. Given its mechanism of action, orlistat has several undesirable side effects including fatty stools, oily spotting, fecal urgency, and flatus with discharge that can occur in 16 to $40 \%$ 
of the patients. ${ }^{9}$ While these side effects can be mitigated by the consumption of a low-fat diet, in real-world use more than $95 \%$ of the patients discontinue treatment within the first year. ${ }^{10}$ In 2015, the Canadian Task Force on Preventative Healthcare recommended against the routine use of orlistat, mainly due to concerns about adverse events.

In 2015, liraglutide (Saxenda ${ }^{\odot}$ ), a glucagon-like peptide-1 (GLP-1) receptor agonist already approved at a lower dose (1.8 $\mathrm{mg}$ ) for type 2 diabetes mellitus, was approved at a higher dose $(3.0 \mathrm{mg})$ for the long-term treatment of obesity. Subsequently, in 2018, a sustained-release combination of naltrexone and bupropion (NB) (Contrave ${ }^{\oplus}$ ) was also approved by Health Canada for long-term obesity treatment. Used individually, NB had already been available for more than 30 years. Naltrexone monotherapy is indicated for the treatment of alcohol and/or opioid dependence. ${ }^{11}$ Bupropion, a norepinephrine-dopamine reuptake inhibitor, is used extensively in primary care to treat mood disorders. ${ }^{12}$ It is also a nicotinic receptor antagonist, and in this context, it is prescribed as a smoking cessation aide. ${ }^{13}$

These novel anti-obesity medications specifically target homeostatic and hedonic mechanisms of food intake. Compared to orlistat, these agents result in greater weight loss, and their gastrointestinal side effects are generally transient. Cardiovascular safety data are more robust than with the previous anti-obesity drugs. Liraglutide reduces major cardiac events in patients with type 2 diabetes with high-risk cardiac profiles. ${ }^{14} \mathrm{~A}$ large, doubleblind cardiovascular safety trial with naltrexone-bupropion was discontinued after results of a scheduled interim analysis, showing possible cardiovascular benefits, became widely known. ${ }^{15}$ As such, these novel agents have the potential to transform obesity care in Canada by addressing the need for treatment options that bridge the gap between behavioral and surgical treatments.

\section{Understanding the role of the brain in energy balance}

Centrally, the hypothalamus is responsible for regulating homeostatic eating behaviors that involve hunger and satiety. Two central nervous system (CNS) pathways regulate energy intake; the orexigenic pathway leads to an increase in food intake, while the anorexigenic pathway leads to a reduction in food intake. Peripheral hormones, including ghrelin released by the stomach, GLP-1 and PYY from the distal gut, insulin from pancreatic beta-cells, and leptin from adipose tissue, cross the blood-brain barrier and regulate food consumption by signaling to these CNS pathways.

The mesolimbic reward system (dopaminergic region of the brain) is responsible for regulating hedonic mechanisms of food intake such as eating for pleasure or in response to cravings. It appears that there are overlapping neurobiological circuits in patients with obesity and those struggling with drug addiction wherein both food and drugs have powerful reinforcing effects moderated by abrupt dopamine surges in the reward centers of the brain. ${ }^{16}$ Progressively, subjects with obesity are conditioned to eat more as the release of dopamine in eating becomes habituated. ${ }^{17}$

The newer anti-obesity medications act by stimulating the hypothalamic anorexigenic pathway, inhibiting the hypothalamic orexigenic pathway, and/or altering the mesolimbic reward system. By altering the physiological drivers for increased energy intake, these medications complement and help sustain the behavioral efforts of patients with obesity by inhibiting pathways that limit weight loss and promote weight regain.

\section{Modes of action}

Liraglutide has $97 \%$ homology to the endogenous GLP-1 secreted by L-cells in the distal gut. It reduces food intake by stimulating the anorexigenic pathway in the hypothalamus and concurrently inhibiting the orexigenic pathway. In addition, liraglutide delays gastric emptying via autonomic inhibition of vagal activity. Overall, there is a decrease in frequency and quantity of food consumption leading to a caloric deficit. ${ }^{18}$

NB works centrally and synergistically to facilitate weight loss. In the hypothalamus, NB stimulates the anorexigenic pathway leading to reduced hunger and food intake. In the mesolimbic region, NB alters reward eating patterns, improving control over eating behaviors and cravings. ${ }^{19}$

\section{Efficacy of anti-obesity medications}

\section{Liraglutide $3.0 \mathrm{mg}$}

The Satiety and Clinical Adiposity Liraglutide Effect (SCALE) Trials included four Phase 3 RCTs. Study subjects were required to have a body mass index (BMI) $\geq 27 \mathrm{~kg} / \mathrm{m}^{2}$ with comorbidities or a $\mathrm{BMI} \geq 30 \mathrm{~kg} / \mathrm{m}^{2}$. Each trial involved randomization to liraglutide or placebo along with standardized lifestyle recommendations including a calorie reduced diet and increased physical activity. ${ }^{20-23}$ Weight loss outcomes are summarized for both the intention to treat analysis group (Table 1) and the completers (Table 2). As expected, the completers experienced more favorable weightloss effects.

SCALE maintenance randomized 422 non-diabetic study subjects 1:1 to liraglutide $3.0 \mathrm{mg}$ or placebo over 56 weeks following a low-calorie diet phase requiring participants to lose at least $5 \%$ of their body weight. ${ }^{20}$ Mean weight loss during the run-in was $6 \%$. In the liraglutide arm, $81.4 \%$ of the study subjects (vs $48.9 \%$ in the placebo group) maintained a $\geq 5 \%$ weight loss achieved in the run-in period. Scale prediabetes randomized 3731 nondiabetic subjects 2:1 to liraglutide 3.0 or placebo over 56 weeks. Primary endpoints at 1 year were: (i) change in body weight; (ii) proportion of study subjects losing $\geq 5 \%$ baseline body weight; and (iii) the proportion of study subjects losing 
Table 1. Liraglutide: weight loss outcomes for the intention to treat analysis group

\begin{tabular}{|c|c|c|c|c|c|c|}
\hline \multirow{2}{*}{$\begin{array}{c}\text { Phase } 3 \\
\text { Clinical trial }\end{array}$} & \multicolumn{2}{|c|}{$\%$ weight change } & \multicolumn{2}{|c|}{$\geq 5 \%$ * } & \multicolumn{2}{|c|}{$>10 \% * *$} \\
\hline & Liraglutide & Placebo & Liraglutide & Placebo & Liraglutide & Placebo \\
\hline $\begin{array}{l}\text { Scale 1: Maintenance } \\
56 \text { weeks }\end{array}$ & 6.2 & 0.2 & 50.5 & 21.8 & 26.1 & 6.3 \\
\hline $\begin{array}{l}\text { Scale 2: Prediabetes } \\
56 \text { weeks }\end{array}$ & 8.0 & 2.6 & 63.2 & 27.1 & 33.1 & 10.6 \\
\hline $\begin{array}{l}\text { Scale 3: Diabetes } \\
56 \text { weeks }\end{array}$ & 6.0 & 2.0 & 54.3 & 21.4 & 25.2 & 6.7 \\
\hline $\begin{array}{l}\text { Scale 4: Apnea } \\
32 \text { weeks }\end{array}$ & 5.7 & 1.6 & 46.3 & 18.5 & 23.4 & 1.7 \\
\hline
\end{tabular}

Data from Scale 1-4 Clinical Trials. ${ }^{20-23}$ *Proportion (\%) of study subjects that lost at least 5\% randomization weight. **Proportion (\%) of study subjects losing more than $10 \%$ randomization weight.

Table 2. Liraglutide: weight loss outcomes for the completers

\begin{tabular}{|c|c|c|c|c|c|c|}
\hline \multirow{2}{*}{$\begin{array}{c}\text { Phase } 3 \\
\text { Clinical trial }\end{array}$} & \multicolumn{2}{|c|}{$\%$ weight change } & \multicolumn{2}{|c|}{$\geq 5 \%$ * } & \multicolumn{2}{|c|}{$>10 \% * *$} \\
\hline & Liraglutide & Placebo & Liraglutide & Placebo & Liraglutide & Placebo \\
\hline $\begin{array}{l}\text { Scale 1: Maintenance } \\
56 \text { weeks }\end{array}$ & 6.7 & 0.1 & 52.7 & 22.7 & 26.1 & 6.3 \\
\hline $\begin{array}{l}\text { Scale 2: Prediabetes } \\
56 \text { weeks }\end{array}$ & 9.2 & 3.5 & 72.8 & 35.7 & 40.9 & 14.9 \\
\hline $\begin{array}{l}\text { Scale 3: Diabetes } \\
56 \text { weeks }\end{array}$ & 6.6 & 2.5 & 58.7 & 20.7 & 27.4 & 7.8 \\
\hline $\begin{array}{l}\text { Scale 4: Apnea } \\
32 \text { weeks }\end{array}$ & 5.7 & 1.6 & 46.3 & 18.5 & 23.4 & 1.7 \\
\hline
\end{tabular}

$>10 \%$ baseline body weight. ${ }^{21}$ Scale diabetes included 846 type 2 diabetic subjects randomized 2:1:1 to liraglutide $3.0 \mathrm{mg}$, liraglutide $1.8 \mathrm{mg}$, or placebo over 56 weeks. Primary endpoints were identical to Scale prediabetes. ${ }^{22}$ Scale sleep apnea randomized in a 1:1 ratio-359 adults with obesity with untreated moderate (apnea-hypopnea index [AHI] 15.0-29.9 events/hour) or severe (AHI $\geq 30$ events/hour) obstructive sleep apnea (OSA) to liraglutide $3.0 \mathrm{mg}$ or placebo for a 32 -week period. ${ }^{23}$ At week 32 , the liraglutide group had a greater reduction in mean AHI compared with placebo ( -12.2 vs -6.1 events/hour).

\section{Naltrexone-Bupropion}

The Contrave ${ }^{\oplus}$ Obesity Research Program (COR) consisted of four 56-week Phase 3 RCTs. All study subjects had body mass indices of $27-45 \mathrm{~kg} / \mathrm{m}^{2}$ and were provided with comprehensive lifestyle recommendations including calorie-reduced diets and increased physical activity. Primary endpoints were percentage change in body weight and proportion of study subjects able to lose $\geq 5 \%$ baseline body weight. ${ }^{24-27}$

COR-1 randomized 1742 study subjects in a 1:1:1 ratio to naltrexone SR $32 \mathrm{mg}$ plus bupropion SR $360 \mathrm{mg}$ (hereafter NB32), naltrexone SR $16 \mathrm{mg}$ plus bupropion $360 \mathrm{mg}$ (NB16), or placebo. ${ }^{24}$ COR-2 randomized 1496 study subjects in a 2:1 ratio to NB32 or Placebo. The co-primary endpoints were assessed at 28 -weeks and re-evaluated at 56 weeks. ${ }^{25}$ COR-BMOD included 793 participants, randomized in a 3:1 ratio to NB32 or placebo. ${ }^{26}$ This study included an intense 56-week behavior modification program that included high-level activity (360 min per week), calorie-reduced nutrition prescriptions, and 28 group therapy sessions led by dieticians, psychologists, and exercise specialists. COR-Diabetes included 505 type 2 diabetics, randomized in a 2:1 ratio to NB32 or placebo. ${ }^{27}$

Weight loss outcomes are summarized for both the intention to treat analysis group (Table 3 ) and the completers (Table 4). 
Table 3. Naloxone-Bupropion: weight loss outcomes for the intention to treat analysis group

\begin{tabular}{|c|c|c|c|c|c|c|}
\hline \multirow{2}{*}{$\begin{array}{c}\text { Phase } 3 \\
\text { Clinical trial }\end{array}$} & \multicolumn{2}{|c|}{$\%$ weight change } & \multicolumn{2}{|c|}{$\geq 5 \%$ * } & \multicolumn{2}{|c|}{$>10 \% * *$} \\
\hline & NB32 & Placebo & NB32 & Placebo & NB32 & Placebo \\
\hline $\begin{array}{l}\text { COR1 } \\
56 \text { weeks }\end{array}$ & 5.4 & 1.3 & 42 & 17 & 21 & 7 \\
\hline $\begin{array}{l}\text { COR } 2 \\
28 \text { weeks } \\
56 \text { weeks }\end{array}$ & $\begin{array}{l}5.9 \\
6.4 \\
\end{array}$ & $\begin{array}{l}2.0 \\
1.6 \\
\end{array}$ & $\begin{array}{l}48.9 \\
47.9 \\
\end{array}$ & $\begin{array}{l}17.1 \\
16.9\end{array}$ & $\begin{array}{l}23.9 \\
39.4 \\
\end{array}$ & $\begin{array}{l}7.4 \\
7.9 \\
\end{array}$ \\
\hline $\begin{array}{l}\text { COR 3: BMOD } \\
56 \text { weeks }\end{array}$ & 8.1 & 4.9 & 57 & 43 & 36 & 18 \\
\hline $\begin{array}{l}\text { COR 4: Diabetes } \\
56 \text { weeks }\end{array}$ & 3.7 & 1.7 & 35 & 21 & 15 & 5 \\
\hline
\end{tabular}

Adapted from Contrave $\circledast$ Product Monograph ${ }^{19}$ COR $1-4,{ }^{24-27}$, and Bausch Health/Orexigen; data on file. *Proportion (\%) of study subjects that lost at least $5 \%$ randomization weight. ** Proportion (\%) of study subjects losing more than $10 \%$ randomization weight.

Table 4. Naloxone-Bupropion: weight loss outcomes for the completers

\begin{tabular}{|c|c|c|c|c|c|c|}
\hline \multirow{2}{*}{$\begin{array}{c}\text { Phase } 3 \\
\text { Clinical trial }\end{array}$} & \multicolumn{2}{|c|}{$\%$ weight change } & \multicolumn{2}{|c|}{$\geq 5 \%$ * } & \multicolumn{2}{|c|}{$>10 \% * *$} \\
\hline & NB32 & Placebo & NB32 & Placebo & NB32 & Placebo \\
\hline $\begin{array}{l}\text { COR1 } \\
56 \text { weeks }\end{array}$ & 8.1 & 1.8 & 61.9 & 23.1 & 34.5 & 10.7 \\
\hline $\begin{array}{l}\text { COR } 2 \\
28 \text { weeks } \\
56 \text { weeks }\end{array}$ & $\begin{array}{l}7.8 \\
8.2\end{array}$ & $\begin{array}{l}2.4 \\
1.4\end{array}$ & $\begin{array}{l}68.8 \\
64.9\end{array}$ & $\begin{array}{l}22.3 \\
21.7\end{array}$ & $\begin{array}{l}35.7 \\
39.4\end{array}$ & $\begin{array}{l}9.4 \\
7.9\end{array}$ \\
\hline $\begin{array}{l}\text { COR 3: BMOD } \\
56 \text { weeks }\end{array}$ & 11.5 & 7.3 & 80.4 & 60.4 & 55.2 & 30.2 \\
\hline $\begin{array}{l}\text { COR 4: Diabetes } \\
56 \text { weeks }\end{array}$ & 5.9 & 2.2 & 53.1 & 24.0 & 26.3 & 8.0 \\
\hline
\end{tabular}

Adapted from Contrave ${ }^{\circledR}$ Product Monograph, ${ }^{19} \mathrm{COR} 1-4,{ }_{1}^{24-27}$ and Bausch Health/Orexigen; data on file. ${ }^{*}$ Proportion (\%) of study subjects that lost at least $5 \%$ randomization weight. * * Proportion (\%) of study subjects losing more than $10 \%$ randomization weight.

Overall, study subjects treated with naltrexone-bupropion experienced statistically greater weight loss outcomes compared to placebo.

Citing the high-quality evidence of the SCALE and COR clinical trials, as well as other clinical trials of anti-obesity medications not approved by Health Canada, existing clinical practice guidelines ${ }^{28}$ strongly recommend incorporating antiobesity medications into the care of patients with obesity. A similar recommendation is expected in a forthcoming update to the adult clinical practice guidelines for obesity management, which is being prepared by Obesity Canada and the Canadian Association of Bariatric Physicians and Surgeons.

\section{Comparison with orlistat}

A network meta-analysis of 28 randomized clinical trials of at least 1-year duration showed that placebo-subtracted weight loss with liraglutide or NB is approximately twice that achieved with orlistat (liraglutide $5.3 \mathrm{~kg}$, NB $5 \mathrm{~kg}$, orlistat $2.6 \mathrm{~kg}$ ). ${ }^{29}$ More patients achieve clinically significant weight loss with these newer medications (Table 5).

Table 5. Percentage of patients achieving clinically significant weight loss at 1 year

\begin{tabular}{|l|l|l|}
\hline \multicolumn{1}{|c|}{$\begin{array}{c}\mathbf{> 5 \%} \\
\text { weight loss }\end{array}$} & \multicolumn{1}{c|}{\begin{tabular}{c}
\multicolumn{1}{c|}{$\mathbf{1 0} \%$} \\
weight loss
\end{tabular}} \\
\hline Placebo & $23 \%$ & $9 \%$ \\
\hline Liraglutide & $63 \%$ & $34 \%$ \\
\hline Naltrexone-bupropion & $55 \%$ & $30 \%$ \\
\hline Orlistat & $44 \%$ & $20 \%$ \\
\hline
\end{tabular}

Data adapted from Khera et al. ${ }^{29}$ 


\section{Obesity medications in clinical practice Indications}

The indications for anti-obesity medications are based on BMI criteria and the presence of weight-related co-morbidities (Box 1). We also consider obesity medications for patients below these BMI cut-offs who may have already lost weight through behavior change, particularly if long-term weight-loss maintenance is a concern. We recommend prioritizing obesity medications for patients with severe comorbidity (e.g., idiopathic intracranial hypertension), a history of weight cycling, and those who are actively gaining weight.

Anti-obesity pharmacotherapy should be used as an adjunct to behavioral modification; these interventions are mutually reinforcing. Anti-obesity medications that decrease appetite encourage adherence to a hypocaloric diet; the additional weight loss achieved with medication may reduce barriers to physical activity. When obesity medication is prescribed in the absence of behavior change, less weight loss is achieved, and patient satisfaction is lower. ${ }^{30}$

More intensive behavioral programs result in greater weight loss; likewise, when combined with pharmacotherapy, more intensive behavioral programs result in greater weight loss. In clinical trials, the standardized lifestyle intervention is easily adaptable to general practice. Subjects are advised to reduce their food intake by 500 kilocalories below their estimated daily requirement, which can be calculated using the Mifflin-St Jeor equation, and participate in aerobic exercise for 150 min weekly. Self-monitoring is also recommended; patients are advised to weigh themselves regularly and maintain a food record. Lifestyle counseling generally occurs every 1-3 months.

\section{Side effects}

Gastrointestinal symptoms are common with liraglutide and NB. To mitigate these side effects, dose escalation over a 4-week period is recommended. Gastrointestinal side effects tend to be mild to moderate in nature and self-limited (Box 2).

\section{Choice of agent}

Initial selection of a weight loss medication is guided by contraindications, co-morbidities, and patient preference. Contraindications for liraglutide are the same as other drugs in GLP-1 agonist class (Box 3). Contraindications for naltrexonebupropion relate to opioid use and conditions that increase the risk of seizure.

We prescribe liraglutide preferentially in patients with diabetes. We typically recommend NB for patients with unmanaged depression, a history of binge drinking, or prior success with smoking cessation using bupropion. Patient preference also plays a role; while many patients prefer an oral to a subcutaneous medication, others highly value single day dosing.
Box 1. Indications for anti-obesity agents

- BMI $\geq 27 \mathrm{~kg} / \mathrm{m}^{2}+$ risk factors, OR

- $\mathrm{BMI} \geq 30 \mathrm{~kg} / \mathrm{m}^{2}$

Adjunct to lifestyle modifications; consider if patient has not lost $0.5 \mathrm{~kg}$ (1lb) per week by 3-6 months after lifestyle changes

Data adapted from Lau et al. ${ }^{6}$

Box 2. Summary of dosing schedules
Orlistat $\left(\mathrm{Xenical}^{\circ}\right)$
- $120 \mathrm{mg}$ TID with meals
Liraglutide $3.0\left(\right.$ Saxenda $\left.{ }^{\circ}\right)$
- $0.6 \mathrm{mg}$ SC daily $\times 1$ week
- $1.2 \mathrm{mg}$ SC daily $\times 1$ week
- $1.8 \mathrm{mg}$ SC daily $\times 1$ week
- $2.4 \mathrm{mg}$ SC daily $\times 1$ week
- $3.0 \mathrm{mg}$ SC daily
Naltrexone SR/Bupropion SR (Contrave ${ }^{\odot}$ )
- 1 tab QD $\times 1$ week
- 1 tab BID $\times 1$ week
- 2 tabs $\mathrm{QAM}+1$ tab $\mathrm{QPM} \times 1$ week
- 2 tabs BID

Data sourced from Xenical ${ }^{\circledR}$, Saxenda ${ }^{\circledR}$, and Contrave ${ }^{\circledR}$ Product Monographs. ${ }^{18,19,30}$

\section{Box 3. Contraindications}

Orlistat $\left(\mathrm{Xenical}^{\oplus}\right)$

- Chronic malabsorption states

- Cholestasis

Liraglutide (Saxenda ${ }^{\oplus}$ )

- Personal or family history of medullary thyroid carcinoma (MTC)

- Patients with multiple endocrine neoplasia syndrome type 2

- Pregnancy or breastfeeding

Naltrexone SR/Bupropion SR (Contrave ${ }^{\circ}$ )

- uncontrolled hypertension

- Seizure disorder or a history of seizures

- Use of other bupropion-containing drugs

- Current or prior diagnosis of bulimia or anorexia

- Chronic opioid or opiate agonist or partial agonist use

- Acute opiate withdrawal

- Abrupt discontinuation of alcohol, benzodiazepines, or other sedatives, and antiepileptic drugs

- Concomitant administration of MAOIs

- Concomitant administration of the antipsychotic thioridazine

- Pregnancy and breastfeeding

- Severe hepatic impairment

- End-stage renal disease

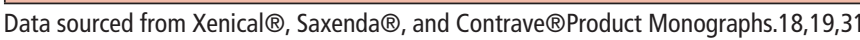


Currently, we are unable to predict which weight loss medication will result in the greatest weight loss for a given individual. If one medication is poorly tolerated or ineffective, another should be trialed. When indicated, obesity medications can be used simultaneously if the expected clinical outcome is to further reduce daily caloric consumption-however, both an increased risk for adverse effects as well as cost-effectiveness must be considered.

\section{Follow-up}

We suggest patient assessment monthly for the first 3 months of medication use, and every 3 months thereafter. ${ }^{31}$ Patients initiated on liraglutide should be monitored for gastrointestinal side effects and injection site reactions. Patients started on NB should be monitored for gastrointestinal side effects, worsening hypertension, tachycardia, anxiety, suicidal ideation, and worsening headaches. Recommended baseline and follow-up investigations are the same as for patients undergoing an isolated behavior intervention. ${ }^{6}$ After 12 weeks at the target dose, an anti-obesity medication should be discontinued if $5 \%$ weight loss has not been achieved. Cross-over trials of obesity medications consistently show accelerated weight regain when medication is stopped. ${ }^{20-23}$ As such, anti-obesity medications, as medications for any other chronic disease (e.g., hypertension, type 2 diabetes, etc.), should be continued indefinitely when they are effective and well-tolerated.

\section{Conclusion}

Obesity treatment has historically been a frustrating aspect of medical practice for primary care practitioners; the long-term outcomes of behavioral therapy are disappointing, bariatric surgery is scarcely available, and medications have been poorly effective. The newest anti-obesity medications target the neurohormonal regulation of appetite, addressing a key mechanism in the pathophysiology of obesity. These medications allow physicians to deliver more effective obesity therapy to a greater number of patients.

\section{Conflicts of Interest}

Authors R.M., S.C., and A.S. have received speaker and consulting honorarium from Novo Nordisk and Bausch Health. Authors R.K and J.D have no conflict of interest to disclose.

\section{References}

1. Statistics Canada. Canadian community health survey. Body mass index, overweight or obese, self-reported, adult, age groups (18 years and older). 2017 [cited 2018 Sept 04].

2. cma.ca [Internet]. Canada: CMA recognizes obesity as a disease; c2018 [cited 2018 Jul 25]. Available from: https://www.cma.ca/En/Pages/cma-recognizesobesity-as-a-disease.aspx
3. Katzmarzyk PT, Ardern CI. Overweight and obesity mortality trends in Canada, 1985-2000. Can J Public Health. 2004;95(1):16-20. http://dx.doi. org/10.1007/BF03403627

4. Puhl RM, Suh Y. Health consequences of weight stigma: Implications for obesity prevention and treatment. Curr Obes Rep. 2015;4(2):182-90. http:// dx.doi.org/10.1007/s13679-015-0153-z

5. Kahan S, Puhl RM. The damaging effects of weight bias internalization. Obesity. 2017;25(2):280-1. http://dx.doi.org/10.1002/oby.21772

6. Lau D, Douketis J, Morrison K, Hramiak I, Sharma A, Ur E. 2006 Canadian clinical practice guidelines on the management and prevention of obesity in adults and children [summary]. CMAJ. 2007;176(8):S1-13. http://dx.doi. org/10.1503/cmaj.061409

7. obesitycanada.ca [Internet]. Canada: Report card on access to obesity treatment for adults in Canada; c2018 [cited 2018 Jun 26]. Available from: https://obesitycanada.ca/publications/ canadians-lack-access-obesity-treatments-support-report-card/

8. James WP, Caterson ID, Coutinho W, Finer N, Van Gaal LF, Maggioni AP, et al. Effect of sibutramine on cardiovascular outcomes in overweight and obese subjects. NEJM. 2010;363(10):905-17. http://dx.doi.org/10.1056/ NEJMoa1003114

9. Davidson M, Hauptman, J, DiGirolamo, M, Foreyt, J, Halsted, C, Heber, D, et al. Weight control and risk factor reduction in obese subjects treated for 2 years with orlistat: A randomized controlled trial. JAMA. 1999;281:235-42. http://dx.doi.org/10.1001/jama.281.3.235

10. Wharton S. Current perspectives on long-term obesity pharmacotherapy. Can J Diabetes. 2016;40(2):184-91. http://dx.doi.org/10.1016/j. jcjd.2015.07.005

11. Naltrexone. Product monograph. Toronto, ON: Teva Canada Limited; 2015.

12. Bupropion Hydrochloride (Wellbutrin). Product monograph. Laval, QC: Valeant Canada LP; 2017.

13. Bupropion Hydrochloride (Zyban). Product monograph. Laval, QC: Valeant Canada LP; 2016.

14. Marso SP, Daniels GH, Brown-Frandsen K, Kristensen P, Mann JF, Nauck $\mathrm{MA}$, et al. Liraglutide and cardiovascular outcomes in type 2 diabetes. NEJM. 2016;375(4):311-22. http://dx.doi.org/10.1056/NEJMoa1603827

15. Nissen SE, Wolski KE, Prcela L, Wadden T, Buse JB, Bakris G, et al. Effect of naltrexone-bupropion on major adverse cardiovascular events in overweight and obese patients with cardiovascular risk factors: A randomized clinical trial. JAMA. 2016;315(10):990-1004. http://dx.doi.org/10.1001/ jama.2016.1558

16. Volkow ND, Wang GJ, Tomasi D, Baler RD. Obesity and addiction: Neurobiological overlaps. Obes Rev. 2013;14(1):2-18. http://dx.doi. org/10.1111/j.1467-789X.2012.01031.x

17. Volkow ND, Wang GJ, Baler RD. Reward, dopamine and the control of food intake: Implications for obesity. Trends Cogn Sci. 2011;15(1):37-46. http:// dx.doi.org/10.1016/j.tics.2010.11.001

18. Saxenda. Product monograph. Mississauga, ON: Novo Nordisk Canada Inc.; 2017.

19. Contrave. Product monograph. Laval, QC: Valeant Canada LP; 2018.

20. Wadden TA, Hollander P, Klein S, Niswender K, Woo V, Hale PM, et al. Weight maintenance and additional weight loss with liraglutide after lowcalorie-diet-induced weight loss: The SCALE maintenance randomized study. Int J Obes (Lond). 2013;37(11):1443-51. http://dx.doi.org/10.1038/ ijo. 2013.120

21. le Roux CW, Astrup A, Fujioka K, Greenway F, Lau DC, Van Gaal L, et al. 3 years of liraglutide versus placebo for type 2 diabetes risk reduction and weight management in individuals with prediabetes: A randomised, doubleblind trial. Lancet. 2017;389(10077):1399-409. http://dx.doi.org/10.1016/ S0140-6736(17)30069-7

22. Davies MJ, Bergenstal R, Bode B, Kushner RF, Lewin A, Skjoth TV, et al. Efficacy of liraglutide for weight loss among patients with type 2 diabetes: The SCALE diabetes randomized clinical trial. JAMA. 2015;314(7):687-99. http://dx.doi.org/10.1001/jama.2015.9676

23. Blackman A, Foster GD, Zammit G, Rosenberg R, Aronne L, Wadden T, et al. Effect of liraglutide $3.0 \mathrm{mg}$ in individuals with obesity and moderate or severe 
obstructive sleep apnea: The SCALE Sleep Apnea randomized clinical trial. Int J Obes (Lond). 2016;40(8):1310-19. http://dx.doi.org/10.1038/ijo.2016.52

24. Greenway FL, Fujioka K, Plodkowski RA, Mudaliar S, Guttadauria M, Erickson J, et al. Effect of naltrexone plus bupropion on weight loss in overweight and obese adults (COR-I): A multicentre, randomised, doubleblind, placebo-controlled, phase 3 trial. Lancet. 2010;376(9741):595-605. http://dx.doi.org/10.1016/S0140-6736(10)60888-4

25. Apovian CM, Aronne L, Rubino D, Still C, Wyatt H, Burns C, et al. A randomized, phase 3 trial of naltrexone SR/bupropion SR on weight and obesity-related risk factors (COR-II). Obesity (Silver Spring). 2013;21(5):93543. http://dx.doi.org/10.1002/oby.20309

26. Wadden TA, Foreyt JP, Foster GD, Hill JO, Klein S, O’Neil PM, et al. Weight loss with naltrexone SR/bupropion SR combination therapy as an adjunct to behavior modification: The COR-BMOD trial. Obesity (Silver Spring). 2011;19(1):110-20. http://dx.doi.org/10.1038/oby.2010.147

27. Hollander P, Gupta AK, Plodkowski R, Greenway F, Bays H, Burns C, et al. Effects of naltrexone sustained-release/bupropion sustained-release combination therapy on body weight and glycemic parameters in overweight and obese patients with type 2 diabetes. Diabetes Care. 2013;36(12):4022-9. http://dx.doi.org/10.2337/dc13-0234

28. Apovian CM, Aronne LJ, Bessesen DH, McDonnell ME, Murad MH, Pagotto $\mathrm{U}$, et al. Pharmacological management of obesity: An endocrine society clinical practice guideline. J Clin Endocrinol Metab. 2015;100(2):342-62. http://dx.doi.org/10.1210/jc.2014-3415

29. Khera R, Murad MH, Chandar AK, Dulai PS, Wang Z, Prokop LJ, et al. Association of pharmacological treatments for obesity with weight loss and adverse events: A systematic review and meta-analysis. JAMA. 2016;315(22):2424-34. http://dx.doi.org/10.1001/jama.2016.7602

30. Wadden TA, Berkowitz RI, Sarwer DB, Prus-Wisniewski R, Steinberg C. Benefits of lifestyle modification in the pharmacological treatment of obesity: A randomized trial. Arch Intern Med. 2001;161(2):218-27. http://dx.doi. org/10.1001/archinte.161.2.218

31. Xenical. Product monograph. Mississauga, ON: Hoffmann-La Roche Limited; 2015. 